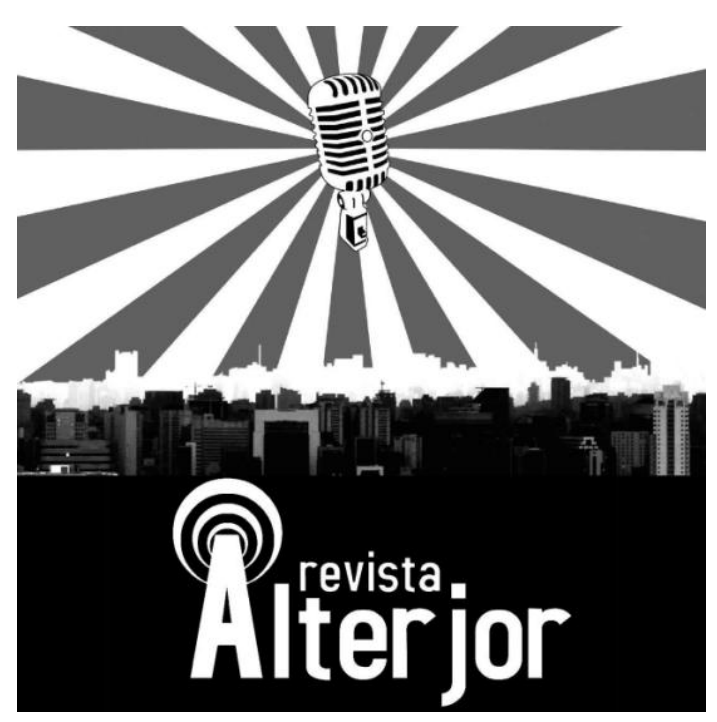

ENTREVISTA

\title{
MARCELO KISCHINHEVSKY - NOVAS PERSPECTIVAS PARA OS ESTUDOS DE PODCAST NO BRASIL
}

\author{
Clara Cavalcanti Rellstab ${ }^{1}$
}

RESUMO: A linguagem dos podcasts está em permanente construção: não se trata de uma mera cópia daquilo que se faz no rádio tradicional, tampouco apresenta originalidade o suficiente para consolidar-se como um meio de linguagem totalmente inovadora. Marcelo Kischinhevsky, doutor pela Universidade Federal do Rio de Janeiro (UFRJ), nesta entrevista, apresenta perspectivas e horizontes para novos estudos a respeito de podcasts, estudos de rádio e linguagem radiofônica na podosfera.

PALAVRAS-CHAVE: podcast. podosfera. rádio. estudos de rádio.

ABSTRACT: The language of podcasts is under permanent construction: it is not a mere copy of what is done on traditional radio, nor presents enough originality to consolidate itself as a totally innovative language. Marcelo Kischinhevsky, Ph.D. at the Federal University of Rio de Janeiro (UFRJ), in this interview, presents perspectives and horizons for new studies on podcasts, radio studies and radio language in the podosphere.

KEYWORDS: podcast; podosphere; radio; radio studies.

\footnotetext{
${ }^{1}$ Mestranda do Programa de Pós-graduação em Ciências da Comunicação da Escola de Comunicações e Artes da Universidade de São Paulo, na área de concentração Ciências da Comunicação, na Linha de Pesquisa II: Processos Comunicacionais: Tecnologias, Produção e Consumos. Bolsista CNPq. E-mail: rellstabclara@gmail.com
}

\section{Revista ALTERJOR}

Grupo de Estudos Alterjor: Jornalismo Popular e Alternativo (ECA-USP)

Ano 12 - Volume 01 - Edição 25 - Janeiro-Junho de 2022

Av. Professor Lúcio Martins Rodrigues, 443, Cidade Universitária, São Paulo, CEP: 05508-020 


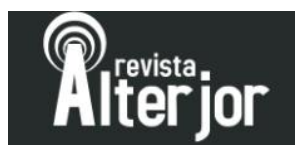

\section{INTRODUÇÃO}

Marcelo Kischinhevsky é diretor do Núcleo de Rádio e TV da Universidade Federal do Rio de Janeiro (UFRJ) e professor dos cursos de Jornalismo e de Rádio e TV da Escola de Comunicação da UFRJ e também do Programa de Pós-Graduação em Comunicação (PPGCOM) da Faculdade de Comunicação Social da Universidade do Estado do Rio de Janeiro (FCS/UERJ). É membro do Conselho Geral da Rede de Rádios Universitárias do Brasil (Rubra).

Nos últimos anos, tem desenvolvido trabalhos que enfocam as indústrias do rádio, da música e do jornalismo, além de desdobramentos da convergência midiática nos campos da cultura e comunicação, com enfoque nos podcasts. Em artigos como "O rádio sem onda: convergência digital e novos desafios na radiofusão" (2007) e "A 'geração podcasting' e os novos usos do rádio na sociedade do espetáculo e do entretenimento" (2008), o pesquisador apresenta seus primeiros estudos a respeito do formato e aqui, nesta entrevista, traça novos horizontes para a pesquisa sobre podcasts no Brasil e suas principais temáticas e desafios.

\section{1) Quais os principais aspectos abordados nos estudos brasileiros e internacionais} que se debruçam sobre o podcast?

O podcasting se torna objeto de pesquisas a partir de 2005 , quando se consagra o neologismo criado por um repórter do The Guardian, em artigo $^{2}$ sobre o que estava acontecendo com o rádio via internet. Desde então, há uma prevalência de abordagens na área de Educação, que enfocam o potencial do áudio como auxiliar no processo de ensino-aprendizagem. Os estudos da área de Comunicação permanecem minoritários e perdem ímpeto com o chamado podfade (período de declínio, passada a euforia inicial, com descontinuidade de inúmeros projetos).

A partir de 2015, no entanto, com o que Tiziano Bonini vai chamar de segunda era do podcasting, há um grande impulso aos estudos sobre o tema. Ainda assim, persiste o

\footnotetext{
${ }^{2}$ Audible revolution. Disponível em:

<https://www.theguardian.com/media/2004/feb/12/broadcasting.digitalmedia>. Acesso em: $10 \mathrm{de}$ dezembro de 2021.
}

\section{Revista ALTERJOR}

Grupo de Estudos Alterjor: Jornalismo Popular e Alternativo (ECA-USP)

Ano 12 - Volume 01 - Edição 25 - Janeiro-Junho de 2022

Av. Professor Lúcio Martins Rodrigues, 443, Cidade Universitária, São Paulo, CEP: 05508-020 


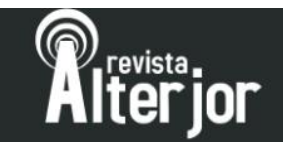

foco no aspecto educacional. Nos estudos de mídia, vemos ênfase nas questões relacionadas ao crescimento do mercado desta modalidade radiofônica e também análises de conteúdo sonoro, ainda rudimentares.

\section{2) Por que a pesquisa sobre podcasts no Brasil permaneceu por tanto tempo em seu maior volume "restrita" ao campo da educação?}

O podcasting esteve associado, nos primeiros anos, ao processo de ensinoaprendizagem, com oferta de cursos por universidades, por exemplo. O mesmo ocorreu nos primórdios do rádio, que era visto por educadores como uma poderosa ferramenta de ensino. Só mais recentemente começamos a procurar entender o objeto em sua complexidade, considerando sobretudo suas dimensões sonoras.

\section{3) Quais as diferenças de linguagem que mais se destacam entre a linguagem radiofônica padrão e a linguagem radiofônica presente nos podcasts?}

Não há diferença substancial. O rádio vem priorizando a lógica do ao vivo, a estética suja, do erro, da redundância, do discurso que vai sendo construído no improviso, no ar. No podcasting, predomina uma estética mais bem cuidada, até porque muitos podcasts são exaustivamente editados, numa perspectiva de montagem aparentada com a do audiovisual. Mas essa lógica do gravado já era comum no rádio hertziano, principalmente no rádio musical, de baixa estimulação. Algumas mudanças vão aos poucos se consolidando, como a supressão de referências temporais ou as repetições de telefones e endereços (algo que fazíamos para o ouvinte do rádio ter tempo de pegar uma caneta e anotar). Hoje, cada vez mais, os conteúdos ao vivo também estão disponíveis sob demanda, eliminando essa necessidade de repetições exageradas (a menos que estas sejam movidas por interesses comerciais, de demarcar a importância de patrocinadores, por exemplo.).

Revista ALTERJOR

Grupo de Estudos Alterjor: Jornalismo Popular e Alternativo (ECA-USP)

Ano 12 - Volume 01 - Edição 25 - Janeiro-Junho de 2022

Av. Professor Lúcio Martins Rodrigues, 443, Cidade Universitária, São Paulo, CEP: 05508-020 


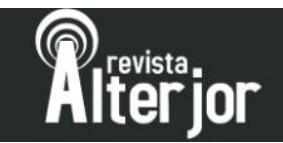

4) Acreditamos que o conceito de podosfera é tão importante quanto o de podcast para que haja entendimento do fenômeno. Concordando ou não comigo, eu gostaria que o senhor me desse a sua definição de podosfera.

Podosfera é uma expressão marketeira, mas que pegou. Abarca o universo de produção, circulação e escuta de podcasts, incluindo aí desenvolvimentos de plataformas, suportes e dispositivos. Com o tempo, fará cada vez menos sentido, como a própria ideia de navegar na internet (a internet hoje permeia diversas atividades cotidianas, tornando-se praticamente transparente; ninguém precisa dizer, numa reportagem, por ex., que determinada entrevista foi feita por e-mail, Discord, Zoom, Jitsi ou Skype). Por ora, algumas pessoas gostam de usar para demarcar um clube (cada vez menos restrito) de pessoas que se aprofundam no universo do podcasting.

\section{5) Quais os principais desafios na pesquisa a respeito do podcast no Brasil?}

Construir metodologias de pesquisa específicas ao objeto. Vejo muita gente fazer "análise de conteúdo" referenciando [Laurence] Bardin, que em seu livrinho dos anos

1970 não fala uma única vez em "rádio" ou "som". É preciso analisar não só o que se diz, mas como se diz, como estes conteúdos circulam, são apropriados pela audiência, ressignificados. Estamos só na infância da pesquisa sobre podcasting, que tem muito a ganhar com o arcabouço teórico-metodológico dos estudos radiofônicos.

\section{REFERÊNCIAS}

BARDIN, L. Análise de Conteúdo. São Paulo: Edições 70, 2011. 